\title{
The Role of Dental Professionals in Pandemic Events and Disaster Responses
}

\author{
Guangwen Li; Bei Chang; Hui Li; Rui Wang; Gang Li
}

\section{ABSTRACT}

The past 20 years have seen major public health emergencies and natural disasters, including the Severe Acute Respiratory Syndrome outbreak caused by the SARS-associated coronavirus (SARS-CoV) in 2003; the Wenchuan earthquake in 2008; and the novel coronavirus pandemic (COVID-19) of 2019, which caused mass casualties, infections, and panic. These also resulted in complex demands for medical resources and information, and a shortage of human resources for emergency responses. To address the shortage of human resources required for these emergency responses, Chinese dental professionals made useful contributions. From this work, deficiencies in emergency response training and opportunities for the expansion of rescue capabilities were identified, and relevant recommendations made.

Key Words: China, dental, public health event, natural disaster, emergency response, novel coronavirus disease (COVID-19)

I $\mathrm{n}$ this century, due to global warming and geological changes, the number and severity of public health events, including outbreaks like the Severe Acute Respiratory Syndrome coronavirus (SARS-CoV), Middle East Respiratory Syndrome coronavirus (MERS$\mathrm{CoV}$ ), and novel coronavirus disease (COVID-19); and natural disasters like earthquakes, have steadily increased. These events resulted in serious challenges to national clinical care and emergency response capabilities in the past, and any increase in the severity of similar situations in the future can lead to the breakdown of the emergency medical rescue system. ${ }^{1-3}$ These public health emergencies and natural disasters also often erupted within a short period, causing large-scale casualties, infections, and mass panic. They also led to complicated demands for medical resources and information, and a shortage of human resources for the respective emergency responses. To avoid further damage from the disasters, first response teams needed to respond in a rapid and coordinated fashion.

Dental professionals could play a role in the response, but this was limited to forensic identification of casualties at disaster scenes, until the idea that dentists could be first responders within the team was introduced in 1996.,5 Gradually, dentists began to be included in interprofessional first responder teams in some comprehensive response plans, ${ }^{5,6}$ and the dental disaster responder role discussed by more medical experts. ${ }^{7}$ In the United States, an act was even signed into law in 2005 in Illinois to modify the scope of the practice of dentistry to include the role of the Dental Emergency Responder (DER) and dental professionals were introduced into federal legislation governing public health response (the Pandemic and All-Hazards Preparedness Act, PAHPA) in $2013 .^{8}$

In the US Military, dentists could act as a part of a medical response team in cases of mass casualty, and they could take part in triage, anesthesia, and maxillofacial surgery in the battlefield environment. ${ }^{4,7}$ A majority of dental responders could also work in mass vaccination with short Just-In-Time training sessions. ${ }^{8}$ There is no doubt that with emergency management training such as Core Disaster Life Support (CDLS) and Basic Disaster Life Support (BDLS), dental professionals could play a more important role in emergency responses. ${ }^{9}$ During past public health emergencies and natural disasters, China's Dental Health Care Personnel (DHCP) contributed usefully to the national emergency response, as described in the following sections. ${ }^{10,11}$

\section{ROLE IN A PUBLIC HEALTH AND MEDICAL EMERGENCY}

The current outbreak of novel coronavirus disease (COVID-19) had been a major epidemic threat in China since December 2019. On January 30, 2020, the World Health Organization (WHO) declared the outbreak of COVID-19 (formerly known as 2019. $\mathrm{nCoV}$ or SARS-CoV-2) a "Public Health Emergency of International Concern" (PHEIC). All 31 provinces and municipalities in China took serious first-level 
measures in response to this national public health emergency. China's National Health Commission (NHC) described the outbreak of COVID-19 as the fastest-spreading public health emergency, with the widest range of infections and the most difficulty of prevention and control, since the founding of the People's Republic of China. WHO estimated that about 30 to 40 countries around the world were at high risk for transmission. By February 29, 2020, COVID-19 had become prevalent on six continents, with 84538 confirmed cases and 2798 deaths, including 78196 confirmed cases and 2718 deaths in China. ${ }^{12-15}$ Some of the epidemic prevention and rehabilitation work that Chinese dental professionals participated in is examined below.

\section{Providing Assistance to Physicians}

Dentists assisted physicians by participating in the general treatment and monitoring of patients with mild pneumonia, including antiviral and antimicrobial therapy, maintaining fluid and electrolyte balance, and monitoring vital signs, biochemical indicators and imaging.

\section{Radiological Diagnosis}

Dental radiologic technicians who specialized in imaging tests like X-ray, Computed Tomography (CT), and Magnetic Resonance Imaging (MRI) participated in the screening and diagnosis of the COVID-19 by High-Resolution Computed Tomography (HRCT). They diagnosed and classified patients according to the scope and type of lesions (early, advanced, and critical stage) displayed by HRCT, which allowed physicians and ICU intensivists to carry out the corresponding treatments.

\section{Specimen Collection}

Dentists also participated in the collection of sputum and nasopharyngeal swab specimens for viral nucleic acid detection, which provided valuable diagnostic information. For specimen collection, ambient light, collection sites, collection methods, collection dwell time, cotton swab disposal, and test tube storage had to be in accordance with regulations. Due to specimen collection being very dangerous work, collection personnel had to take strict tertiary protection measures, including wearing N95 masks, rubber gloves, isolation protective clothing, and goggles.

\section{Nursing Work}

Dental nurses were involved in the care of mild cases of COVID-19, including closely monitoring body temperature, breathing rhythm and frequency, blood oxygen saturation, and other vital signs. They also followed physician orders, helped reduce fever, and monitored fluid, electrolyte and acid-base balance; liver and kidney function; nutritional status; and clinical symptoms. In addition, after training, they also participated in medical work, such as venous access care, oxygen therapy preparation, assisting patients who required mechanical ventilation with non-invasive ventilators, assisting physicians in establishing artificial airways, and so on.

\section{Online Consulting and Prescribing}

The demand for medical care has increased due to the coronavirus pandemic, but it was not convenient for patients to go to the hospital for medical treatment. Dental professionals conducted medical consultations through online consultation platforms, including answering patients' questions, relieving patients' anxiety, and prescribing required medications. In this way, they helped reduce the admission of mild cases to the hospital, and reduced the risk of cross infection.

\section{Collecting and Distributing Medical Supplies}

Dental professionals participated in the collection of medical protective equipment such as masks, goggles, and disposable protective clothing. They also assisted hospital logistics personnel with counting and handing out protective equipment and medicines.

\section{Medical Evacuation and Transfer}

Dental professionals participated in the medical evacuation and transfer of suspected and confirmed cases of COVID-19 with negative pressure ambulances, paying special attention to the airway management and vital signs of patients during transit. Moreover, the dentists comforted the patients with good communication skills and disinfected the vehicles after transit.

\section{Community Volunteering}

Dentists were well-versed in community infection control. They helped quarantine suspected cases, monitored temperature by infrared thermometer, registered personal information, provided COVID-19 prevention knowledge, assessed the management of community personnel and vehicles, recycled used masks, and disinfected the community environment.

\section{Psychological Comfort}

The outbreak of COVID-19 had the potential to cause panic and trigger overblown anxiety in the population. Dental professionals participated in sharing knowledge about COVID-19, comforting people over the phone or online, relieving their stress and anxiety, and enhancing their confidence in successful resolution of the COVID-19 pandemic.

\section{ROLE IN A NATURAL DISASTER}

Data from the China National Commission for Disaster Reduction confirmed that more than 100 major natural disasters have occurred in China in the past 20 years, of which meteorological and hydrological disasters account for $71.8 \%$, geological disasters $27.3 \%$, and marine disasters $0.9 \%$. In terms of the frequency of different disasters, heavy rain, floods, typhoons, earthquakes, landslides, and mudslides accounted for $78.1 \%$ of the major disasters. Geological disasters have caused far more deaths than other disasters. ${ }^{16}$ Dental Professionals participated mainly in earthquake rescue operations. 


\section{Emergency Management of Oral and Maxillofacial Trauma}

Oral and Maxillofacial Surgeons (OMS) could carry out treatment of mandibular fractures, temporomandibular joint injuries, and other injuries of the hard and soft tissues of the oral and maxillofacial region, as well as post-operative rehabilitation. Dentists could also deal with dental trauma such as tooth dislocation, fracture, shock, and contusion, and oral mucosa trauma caused by disaster, and provide follow-up dental treatment. ${ }^{16-18}$

\section{Participating in First Aid}

In China, dentists are trained in surgery and medicine at the undergraduate level, so they were capable of giving surgical treatment to patients with mild injuries, apart from dentoalveolar injuries. They could provide field first aid treatments including needle cricothyroidotomy, cardiopulmonary resuscitation, hemostasis, bandaging, fixation, and transportation. Symptomatic and supportive treatment could also be provided, according to medical condition, on site. During treatment, dentists who had experience in sedation dentistry could reduce the patients' anxiety, discomfort, and pain, by sedation. In scenarios like this, all measures including emotional support should be taken to reduce mortality and disability, if possible. ${ }^{18}$

\section{The Triage and Medical Evacuation of the Injured}

A large number of casualties could occur in an earthquake, leading to a shortage of medical personnel and supplies. As a result, not all the injured may be immediately treatable. Triage could help determine the medical priority of the injured, and increase the number of survivors. Dentists could provide assistance in triage procedures, and classify the injured into five categories based on the principles and methods of classification. ${ }^{17,19}$

Red tags (immediate) indicated the injured who had a chance of survival if they were treated immediately. They required high priority treatment or transfer.

Yellow tags (delayed) indicated the injured who were not in danger of death at the moment, but required hospital care later. They were of medium priority.

Green tags (minor) indicated ambulatory patients in stable condition, who needed medical care.

Black tags (deceased/expectant) indicated dead or moribund patients.

White tags (dismiss) indicated people with minor injuries who could recover without medical care.

\section{Trauma Care}

Dentists could participate in nursing and vital signs monitoring before and after surgery, establishing venous access for anti-shock and anti-microbial treatment. They could also assist surgeons in debridement and disinfection to promote wound healing due to their Infection prevention and control training and daily work. ${ }^{17}$

\section{Providing Wards for the Injured}

The department of oral and maxillofacial surgery could provide vacant wards and beds to the injured, and dentists could assist surgeons with taking in and managing postoperative patients. $^{17}$

\section{Provision of Oral Health Services}

Oral health is also difficult to maintain for rescuers and earthquake victims in temporary shelters. The poor oral health due to harsh living conditions and psychological stress can easily cause gingivitis, pulpitis, periodontitis, ulcers, and lichen planus. The normal medical infrastructure and dental facilities were seriously damaged in the earthquake. Dentists could deal with the oral disease with portable dental equipment, relieving the suffering of the patients. ${ }^{17}$

\section{Donation of Dental Care Products and Provision of Oral Health Education}

Prevention is very important. A lack of medicines and dental care products such as toothpastes, toothbrushes, floss, and mouthwashes may lead to poor oral health, and oral diseases might occur easily as a result. In these natural disasters, dentists could procure and donate medicines and dental care products to rescuers and victims, helping to reduce oral diseases. Dentists could also provide guidance to maintain the oral health of individuals with pre-existing conditions, through educational materials, lectures, posters, and dental counseling. 17,19

\section{FUTURE DEVELOPMENT}

Chinese dental professionals have played a role in public health events and natural disasters over the past 20 years. However, as China's emergency response research and institutional mechanisms are still in their infancy, there is a gap between China and developed countries in terms of legal authorization and professional training. The role of Chinese dental professionals in public health events and natural disasters is therefore still limited. Fortunately, the Chinese government has recognized the inadequacy of the national emergency response mechanism and has gradually begun to improve the national public health emergency management system, especially after the recent outbreak of COVID-19. Dental professionals, who may be included in the national public health emergency management system in the near future, need to be developed in some of the ways below, to be able to play a more important role.

\section{Strengthening the Legal System}

With the improvement of China national public health emergency management system, the Chinese Stomatological 
Association can promote a "Dental Emergency Responder Act," similar to the United States. ${ }^{7}$ The law and regulations can authorize dental professionals to participate in emergency responses, and regulate their duties, participation methods, and processes in the national public health emergency management system. ${ }^{20,21}$

\section{Regular Training Plan}

Public health emergency training could also be made a necessary skill for dental students in universities, and incorporated into curriculum assessments. Targeted training could also be carried out on regional emergency responses like major epidemics or disasters. The National Health Commission of the People's Republic of China, and the Chinese Medical Doctor Association, could provide free and regular public health emergency courses and training at different levels, serving as a national continuing medical education project for inservice dental professionals. In addition to professional training in oral first aid and oral health, emergency management training such as Core Disaster Life Support (CDLS), Basic Disaster Life Support (BDLS), Advanced Disaster Life Support (ADLS), infection control, triage, and so on, should also be added. ${ }^{22,23}$

\section{Organizing Emergency Drills}

Regional just-in-time (JIT) emergency drills could be carried out from time to time to help dentists apply the knowledge and skills they have learned in practice. Team communication and cooperation among dentists, physicians, surgeons, and logistical personnel could be strengthened by the emergency drills. ${ }^{23}$

\section{Immunizations}

During epidemics, pathogens could spread easily from person to person and cause serious illness locally and even worldwide. Everyone is at risk of contracting illnesses that humans have little or no immunity to. Large numbers of vaccinators are therefore needed to carry out rapid population immunization. Dental professionals should receive regular immunization training to ensure that they can participate in mass immunization programs at short notice. Dental hospitals and clinics can also be temporarily requisitioned as immunization sites. ${ }^{24}$

\section{Identification}

Disaster Victim Identification (DVI) plays an important role in disasters, especially with the large number of casualties caused by floods and earthquakes. One of the most reliable identification methods of identifying individual victims is through dental evidence. Dental identification is even superior to other methods, as teeth are the hardest substances in the human body, and a good reservoir of DNA material that can withstand hostile environments. There is however still a long way to go in the forensic odontology of China, and the ability of these professionals to participate in DVI is limited.
In the future, forensic dentistry committees could be set up to develop the discipline and train personnel. A database of dental models could also be established, which could be helpful in dental identification, including DVI..$^{25-27}$

\section{CONCLUSION}

We have summarized the work of Chinese dental professionals in the public health emergencies represented by COVID-19 and natural disasters like the Wenchuan earthquake, and brought forward ways in which dental professionals could be included in the national public health emergency management system. Dental professionals could participate in diagnosis, treatment of cases, radiography, specimen collection, online consulting and prescribing, distributing medical supplies, medical evacuation and transfer, community infection control, comforting, and so on, in public health emergencies. They could also take part in the emergency management of oral and maxillofacial trauma, first aid, triage and medical evacuation of the injured, trauma care, provision of oral health services, and so on, in natural disasters. The terrible memories of the SARS-Cov outbreak and the Wenchuan earthquake have still not disappeared from people's minds. COVID-19 has also emerged recently. When faced with massive casualties, infections, and mass panic, the medical care system in an area could be overwhelmed. Dental professionals have contributed a lot in personnel and facilities to emergency responses, based on their scientific and technical skills. Regular training and emergency drills are however still needed for dental professionals, which could make them more effective emergency responders. Dental professionals should work together with emergency response communities, and play a more important role in future responses.

\section{About the Authors \\ State Key Laboratory of Military Stomatology, National Clinical Research Center for Oral Diseases, Department of Preventive Dentistry, School of Stomatology, Shaanxi, and Air Force Military Medical University, Xi'an, Shaanxi Province, China (Guangwen Li, Gang Li); The PLA Rocket Force Characteristic Medical Center, Beijing, China (Bei Chang); School of Public Health, Southwest Medical University, Luzhou, Sichuan Province, China (Hui Li) and Department of Medical Education, Tangdu Hospital, Air Force Military Medical University, Xi'an, Shaanxi Province, China (Rui Wang).}

Correspondence: Hui Li, (e-mail: feslgw_4138@163.com) and Gang Li (e-mail: ligangi@fmmu.edu.cn).

\section{Acknowledgements}

The authors would like to thank the School of Stomatology, Air Force Military Medical University, Lei Wang, and Jing Guo, for their participation and assistance.

\section{Conflict of interest statement}

The authors declare no conflicts of interest.

\section{Author Contributions}

Guangwen Li and Bei Chang contributed equally to this work. 


\section{References}

1. Carballo M, Nerukar A. Migration, refugees, and health risks. Emerging Infect Dis. 2001;7(3 Suppl):556-560.

2. Reinhardt JD, Li J, Gosney J, et al. Disability and health-related rehabilitation in international disaster relief. Global Health Action. 2011;4:7191.

3. Burkholder BT, Toole MJ. Evolution of complex disasters. Lancet. 1995; 346(8981):1012-1015.

4. Morlang WM. Dentistry's vital role in disaster preparedness. J Calif Dent Assoc. 1996;24(5):63-66.

5. Colvard MD, Vesper BJ, Kaste LM, et al. The Evolving Role of Dental Responders on Interprofessional Emergency Response Teams. Dent Clin North Am. 2016;60(4):907-920.

6. US Department of Health and Human Services. National health security strategy of the United States of America. Washington, DC: US Department of Health and Human Services; 2009.

7. Colvard MD, Lampiris LN, Cordell GA, et al. The dental emergency responder: expanding the scope of dental practice. J Am Dent Assoc (1939). 2006;137(4):468-473.

8. Colvard MD, Hirst JL, Vesper BJ, et al. Just-in-time training of dental responders in a simulated pandemic immunization response exercise. Disaster Med Public Health Prep. 2014;8(3):247-251.

9. Colvard MD, Naiman MI, Mata D, et al. Disaster medicine training survey results for dental health care providers in Illinois. J Am Dent Assoc. 2007;138(4):519-524.

10. Liang XH, Tang YL, Luo E, et al. Maxillofacial injuries caused by the 2008 Wenchuan earthquake in China. J Oral Maxillofac Surg. 2009; 67(7):1442-1445.

11. Li R, Wang H, Xiao J, et al. Maxillofacial injuries in the Wenchuan earthquake. J Trauma. 2010;69(6):1481-1485

12. World Health Organization. Novel Coronavirus (2019-nCoV) Situation Report -11. World Health Organization; 2020.

13. Chan JF, Yuan S, Kok KH, et al. A familial cluster of pneumonia associated with the 2019 novel coronavirus indicating person-to-person transmission: a study of a family cluster. Lancet. 2020;395(10223):514-523.

14. Chen N, Zhou M, Dong X, et al. Epidemiological and clinical characteristics of 99 cases of 2019 novel coronavirus pneumonia in Wuhan, China: a descriptive study. Lancet. 2020;395(10223):507-513.
15. National Health Commission of the People's Republic of China. The latest situation of novel coronavirus pneumonia as of 24:00 on 7 March, 2020. National Health Commission of the People's Republic of China; 2020.

16. Dai J, Zhao Y, Li G. Wenchuan earthquake: response of Chinese dental professionals. Br Dent J. 2009;206(5):273-276.

17. Wang L, Wei JH, He LS, et al. Dentists' role in treating facial injuries sustained in the 2008 earthquake in China: how dental professionals can contribute to emergency response. J Am Dent Assoc. 2009;140(5): 543-549.

18. Li R, Wang H, Guo L, et al. Analysis of maxillofacial fracture victims in the Wenchuan earthquake and Yushu earthquake. Dent Traumatol. 2010; 26(6):454-458.

19. Tang YL, Zhu GQ, Zhou H, et al. Analysis of 46 maxillofacial fracture victims in the 2008 Wenchuan, China earthquake. Oral Surg Oral Med Oral Pathol Oral Radiol. 2009;108(5):673-678.

20. More FG, Phelan J, Boylan R, et al. Predoctoral dental school curriculum for catastrophe preparedness. J Dent Educ. 2004;68(8): 851-858.

21. Glotzer DL, More FG, Phelan J, et al. Introducing a senior course on catastrophe preparedness into the dental school curriculum. J Dent Educ. 2006;70(3):225-230.

22. Coule PL, Horner JA. National disaster life support programs: a platform for multi-disciplinary disaster response. Dent Clin North Am. 2007;51(4): 819-825.

23. Chmar JE, Ranney RR, Guay AH, Haden NK, Valachovic RW. Incorporating bioterrorism training into dental education: report of ADA-ADEA terrorism and mass casualty curriculum development workshop. J Dent Educ. 2004;68(11):1196-1199.

24. Galligan JM. Dentists can contribute expertise in a major public health disaster. J Calif Dent Assoc. 2004;32(8):701-708.

25. Brannon RB, Morlang WM, Smith BC. The gander disaster: dental identification in a military tragedy. J Forensic Sci. 2003;48(6): 1331-1335.

26. Brannon RB, Morlang WM. The USS Iowa disaster: success of the forensic dental team. J Forensic Sci. 2004;49(5):1067-1068.

27. Morlang WM, Wright LS. Lessons from the Big Thompson Canyon. Gen Dent. 1978;26(5):36-39. 